\title{
Automatic IM Parameter Measurement Under Sensorless Field-Oriented Control
}

\author{
Yih-Neng Lin
}

\section{Chern-Lin Chen}

Power Electronics Laboratory

Department of Electrical Engineering

National Taiwan University

Taipei, Taiwan 10764

\begin{abstract}
A novel approach of automatic induction motor(IM) parameter measurement under sensorless field-oriented control(FOC) is presented. No additional hardware is required in this approach. Before start-up, the inverter drive automatically performs the dc test, the no-load test, and the locked-rotor test for the driven $\mathrm{IM}$. Only input current signals are measured and sent to the field-oriented controller. The concepts of no-load test and $\mathrm{dc}$ test can be modified under the FOC structure. The conventional locked-rotor test requires that the rotor shaft has to be locked mechanically. This prohibits automatic measurement by the FOC inverter drive. A pseudo locked-rotor test for FOC structure is presented in this paper to facilitate automatic $\mathbb{I M}$ measurement. The test data are then computed to get the IM parameters and the exciting current command for FOC. The presented method has been tested on a 3 -hp inverter-driven motor system. Its effectiveness is illustrated by experimental recordings.
\end{abstract}

\section{INTRODUCTION}

In most applications, ac machines are preferable to dc machines due to their simple and robust construction[1]. The field-oriented control (FOC) concept [2] has become a standard tool for high-performance control of ac motors because it gives control characteristics similar to a separately excited dc motor. In the case of IM drive systems, the FOC needs a speed sensor such as a shaft encoder for good performance. However, it is different to meant a speed sensor on the MM shaft in some cases, such as motor drives in hostile environments or high speed motor drives. Several FOC methods without speed sensors have been proposed [3-6]. Rapid developments in the sensorless FOC technology may be expected in industrial applications.

Sensorless FOC requires accurate $\mathbb{I M}$ parameters. Generally every installation requires specific tuning for adapting to different motors[7]. However, the IM parameters measured by conventional tests, the dc test, the no-load test, and the locked-rotor test[8], are not directly applicable under FOC. The concepts of no-load test and dc test can be modified for the FOC structure. The exciting current command can be obtained in the no-load test under sensorless FOC. The conventional locked-rotor test requires that the rotor shaft has to be locked mechanically. This prohibits automatic measurement by the FOC inverter drive. The mechanical locking of the rotor shaft can be omitted by substituting the three-phase locked-rotor test with a pseudo locked-rotor test[9]. This

This work was supported in part by National Science Council, Taiwan and TECO CO., LTD. under the contract NSC 84-2622-E011-005 test is especially appropriate for V/f inverter-driven motor systems and would be modified in this paper for FOC. A fully-automatic measurement system for IM parameters is developed. No extra hardware is needed in these tests. Only input current signals are measured and sent to the controller. Experiments are performed to verify the effectiveness of the proposed methods.

\section{SENSORLESS FOC OF IM}

\section{A. Model of Induction Machine}

The dynamic $D-Q$ model of ac machines $[8]$ is used. Shown in Fig. 1 is the combined per-phase equivalent circuit for the $d^{s}-q^{s}$ equivalent circuits with counter emf.

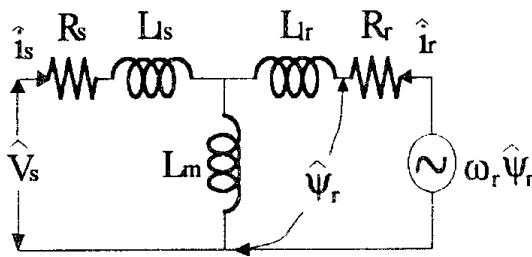

Fig. 1 The per phase circuit with counter emf.

$\left|\hat{v_{s}}\right|=\sqrt{v_{q s}^{2}+v_{d s}^{2}}$

$\left|\hat{\psi}_{r}\right|=\sqrt{\psi_{q r}^{s^{2}}+\psi_{d r}^{s^{2}}}$

$\mathrm{R}_{s}, \mathrm{R}_{r}, \mathrm{~L}_{\mathrm{s}}, \mathrm{L}_{i r}, \mathrm{~L}_{\mathrm{m}}$ may be derived directly from conventional dc test, no-load test and locked-rotor test. Voltages and currents in this dynamic model can be represented in the complex plane.

$\left[\begin{array}{c}\hat{V}_{s} \\ 0\end{array}\right]=\left[\begin{array}{cc}R_{s}+p\left(L_{L_{s}}+L_{m}\right) & p L_{m} \\ \left(p-j \omega_{m}\right) L_{m} & R_{r}+\left(p-j \omega_{m}\right)\left(L_{m}+L_{l r}\right)\end{array}\right]\left[\begin{array}{l}\hat{i}_{s} \\ \hat{i}_{r}\end{array}\right]$

where $p=d / d t$ is the differential operator

$\omega_{m}$ is the electrical speed of rotor

$\hat{V}_{s}=v_{q s}-j v_{d s}$

$\hat{i}_{s}=i_{q s}^{s}-j i_{d s}^{s}$

$\hat{i}_{r}=i_{q r}^{s}-j i_{d r}^{s}$

B. Sensorless FOC

A simple sensorless FOC with space-vector based current controller for PWM-inverter is shown in Fig 2. The system consists of hardware and software. The hardware is voltage source inverter(VSI) connecting to IM. 


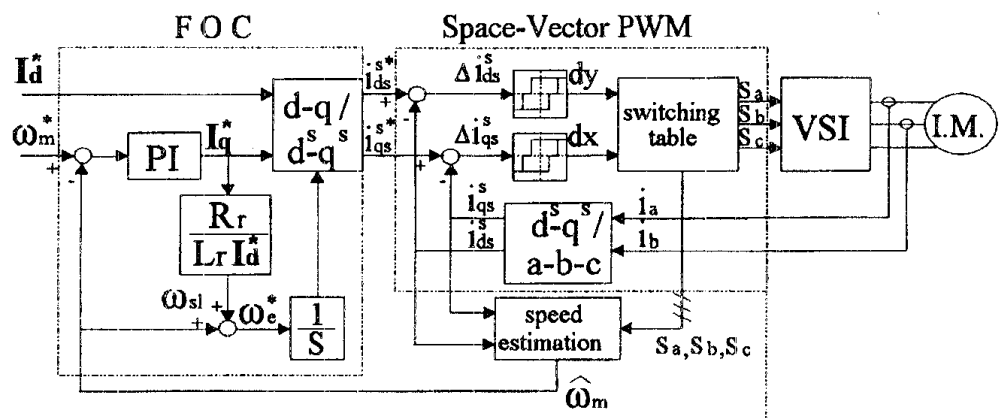

Software

Hardware

Fig. 2 Block diagram of sensorless FOC.

The software forms in FOC, space-vector PWM and rotor speed estimation. For sensorless FOC, it is desirable that

$\frac{d\left|\hat{i}_{m}\right|}{d t}=0$

$\left|\hat{i_{m}}\right|=I_{d}^{*}$

$\omega_{s l}=\frac{R_{r} \cdot I_{q}^{*}}{L_{r} \cdot I_{d}^{*}}$

$\omega_{e}^{*}=\omega_{s l}+\hat{\omega}_{m}$,

where $\hat{i}_{m}$ is the exciting current, $\hat{i}_{m}=\hat{i}_{s}+\hat{i}_{r}$

$\omega_{s l}$ is the slip frequency

$\hat{\omega}_{m}$ is the estimation of electrical angular velocity $\omega_{e}^{*}$ is the command of electrical angular velocity

The transformation between the rotationary coordinate system and the stationary system is

$\left[\begin{array}{c}i_{q s}^{s^{*}} \\ i_{d s}^{s^{*}}\end{array}\right]=\left[\begin{array}{cc}\cos \rho(t) & \sin \rho(t) \\ -\sin \rho(t) & \cos \rho(t)\end{array}\right]\left[\begin{array}{c}I_{q}^{*} \\ I_{d}^{*}\end{array}\right]$

where $\rho(t)=\int \omega_{e}^{*} d \tau$

For space-vector based current controller, it is desirable that an output current space-vector follows commands $i^{s}$ and $i_{d s}^{s^{s}}[11]$. By comparing the commands $i_{q s}^{s^{*}}$ and $i_{d s}^{s^{s *}}$ with the practical currents $i_{q s}^{s}$ and $i_{d s}^{s}$, the digital output signals $(\mathrm{dx}, \mathrm{dy})$ can be obtained. Then, the digital output signals $(\mathrm{dx}, \mathrm{dy})$ of the comparators select the state of inverter switches ( $\mathrm{Sa}, \mathrm{Sb}, \mathrm{Sc}$ ) according to Table I. This table defines the inverter output voltage. Furthermore, there are eight different voltage vectors in an inverter Each output voltage vector of the inverter is shown in Fig 3.

TABLE I SWITCHING TABLE

\begin{tabular}{|c|c|c|c|}
\hline $\mathrm{dy} / \mathrm{dx}$ & -1 & 0 & 1 \\
\hline 1 & $\mathrm{u} 5$ & $\mathrm{u} 6$ or us & $\mathrm{u} 6$ \\
\hline 0 & $\mathrm{u} 4$ & $\mathrm{u} 0$ & $\mathrm{u} 1$ \\
\hline-1 & $\mathrm{u} 3$ & $\mathrm{u} 3$ or u2 & $\mathrm{u} 2$ \\
\hline
\end{tabular}

Since the primary voltage $\hat{V}_{s}$ can be obtained by the switching table ( $\mathrm{Sa}, \mathrm{Sb}, \mathrm{Sc}$ ) and primary current $\hat{i}_{s}$ can be detected by serisors, the rotor speed of IM can be estimated.

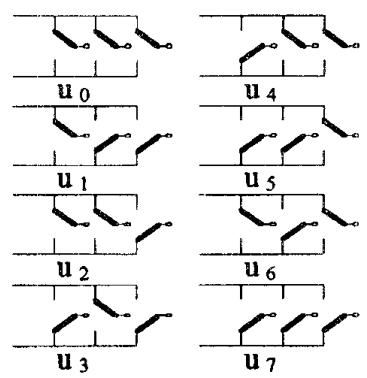

Fig.3 Eight output voltage vectors.

\section{PARAMETER MEASUREMENT}

IM parameters are conventionally determined by the dc test, the no-load test and the locked rotor test. In this section, these three tests are modified for automatic parameter measurement of $\mathrm{IM}$ under sensorless FOC.

\section{A. Dc Test}

In the automatic dc test, the inverter has to play the role of an additional dc power supply for measuring stator winding resistance. Shown in Fig.4(a) is the connection of the inverter and the three stator windings. In this modified test, the same control signals are applied to the phase $b$ and the phase $c$ legs of the inverter. In this way, the phase $b$ leg of the inverter is equivalently short to the phase c. The inverter phase a output current is sent into the phase a winding and is shared by phase $b$ and phase $c$. The current in the phase a winding is adjusted to the rated value, and the voltage between the terminals is measured. The current in the stator windings is adjusted to heat the windings to the temperature they would have during normal operation[8]. The equivalent circuit is shown in Fig. 4(b) and the stator winding resistance can be found.

$R_{s}=\frac{2}{3} \frac{V_{a b}}{l_{a}}$ 
Fig. 4(c) shows the command modifications for this test. $I_{d}{ }^{*}=0, I q^{*}=I_{r a t e d}$, and $\omega_{e^{*}=0}$ are specified. Under this condition

$i_{q s}^{s^{*}}=I_{q}^{*}=I_{\text {rated }}$

$s_{d s}^{s^{*}}=0$

The terminal current command, Irated is dc. In addition, for applying the same control signals to phase $b$ and phase $c, d y$ is forced zero in the space vector modulator. In this way, only two vectors, ul \& $u 4$, are utilized. The complete control flow for the modified dc test is shown in Fig 4(d). No extra measuremant is required.

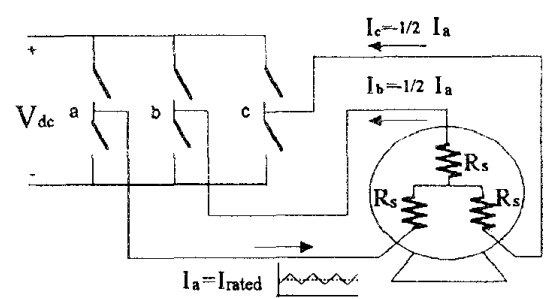

(a) Inverter-motor connection

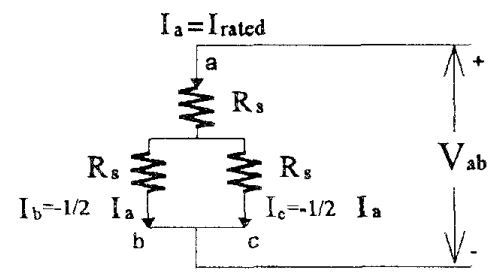

(b) Equivalent circuit

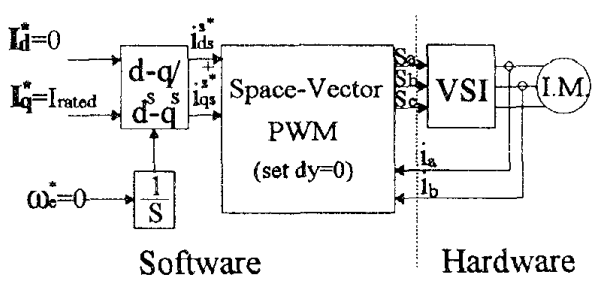

(c) Block diagram

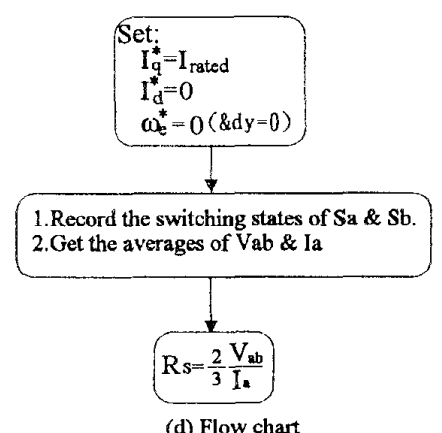

Fig. 4 The modified de test.
Phase $a$ is fed with the current which consists of $d c$ and switching-frequency ripple currents. Inaccurate test results may appear due to the switching ripple effects. To minimize the switching effects, three test values under different switching frequencies are considered. A 2ndorder polynomial is constructed

$p_{k}\left(x_{k}\right)=a_{2} x_{k}^{2}+a_{1} x_{k}+a_{0}$,

where $p_{k}$ (.) for $\mathrm{k}=0,1,2$ are the test values

$x_{k}$ for $\mathrm{k}=0,1,2$ are the different switching frequencies

The $a_{0}$ is then the estimate for the conventional dc test. It represents the $\mathrm{dc}$ stator winding resistance which is measured under $\mathrm{dc}$ current.

The $a_{0}$ may be solved by the Cramer's rule[12]

$a_{0}=\frac{1}{|X|}|X(3 ; P)|$,

where $X=\left[\begin{array}{lll}x_{k}^{2} & x_{k} & 1\end{array}\right]$,

$$
X(3 ; P)=\left[\begin{array}{lll}
x_{k}^{2} & x_{k} & p_{k}
\end{array}\right] \text { for } \mathrm{k}=0,1,2 \text {. }
$$

\section{B. No-load Test}

The conventional no-load test provides the information about the magnetization inductance $\mathrm{Lm}$ and its magnetization current. The test setup for the conventional no-load test is shown in Fig, 5(a). Two wattmeters, a voltmeter, and three ammeters are used. The $\mathbb{M}$ equivalent circuit under the no-load test is shown in Fig 5(b). The equivalent input impedance is thus approximately[8]

$$
\begin{aligned}
& \left|Z_{e q}\right|=\frac{V_{\phi}}{I_{n l}} \approx X_{l s}+X_{m} \\
& \left|R_{e q}\right|=\left(P_{1}+P_{2}\right) /\left(3^{*} I_{n l}^{2}\right) \\
& \left|X_{e q}\right|=\sqrt{Z_{e q}^{2}-R_{e q}^{2}} \\
& L_{m}+L_{l s}=X_{e q} / \omega_{e}
\end{aligned}
$$

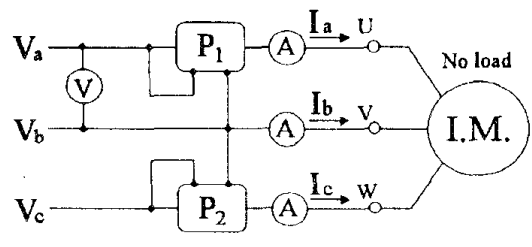

(a) Test circuit

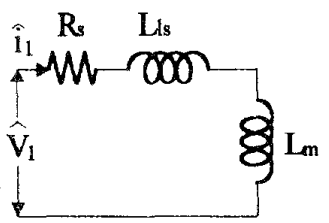

(b) Equivalent circuit

Fig. 5 The conventional no-load test. 
Three commands $I_{d}^{*}, I_{q}{ }^{*}$, and $\omega_{e}{ }^{*}$ are modified in the proposed automatic no-load test, as shown in Fig. 6(a). Initially, $\omega_{e}^{*}=\omega_{\text {rated, }} \mathrm{Iq}^{*}=0$, and $\mathrm{Id}^{*}=$ Irated. During the test, $I_{d}^{*}$ is gradually adjusted down to an appropriate noload value. Before $\mathrm{Id}_{\mathrm{d}}^{*}$ reaches its no-load value, the threephase inverter output voltage will be unbalanced. Fig. 6(b) displays unbalanced output voltages when $\mathrm{Id}^{*}$ is larger than terminal current. The space-vector based current controller performs voltage vectors u6, u2, u3 and u5 in a cycle. Upon three-phase balance is achieved, $I^{*}$ is the desirable command for no-load test. The complete control flow for the modified no-load test is shown in Fig. 6(c).

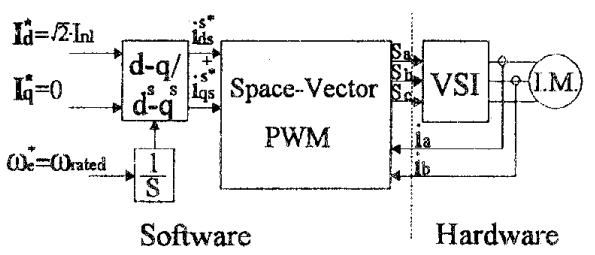

(a) Block diagram

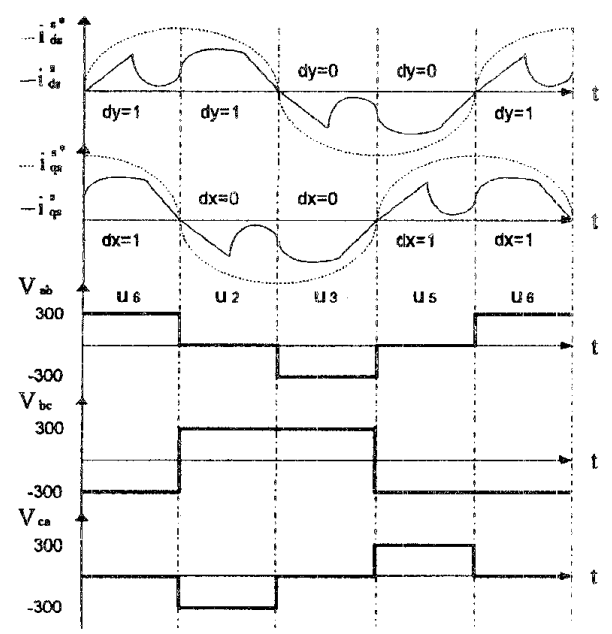

(b) Unbalanced output voltages

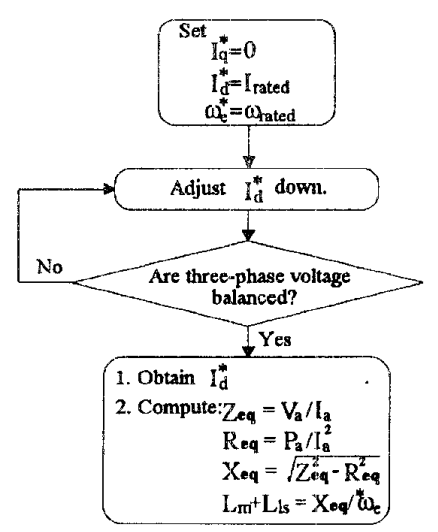

(c) Flow chart

Fig. 6 The modified no-load test.

\section{Locked-Rotor Test}

To perform the locked-rotor test, the rotor has to remain stationary. Conventionally, the rotor shaft is locked mechanically during this test. For fully-automatic lockedrotor test, the mechanical locking is removed and the rotor stands still during test[9].

The automatic pseudo locked-rotor test can be performed under sensorless FOC. Three commands are modified, $\mathrm{Id}^{*}=0, \mathrm{Iq}^{*}=\mathrm{Irated}$, and $\omega_{\mathrm{e}}{ }^{*}=0.25 \omega_{\text {rated, as shown }}$ in Fig. 7(a). The normal operating frequency of the rotor is not the same as the stator. A typical cornpromise is to use a frequency $25 \%$ or less of the rated frequency[8].

The current command $i_{q s}^{s^{*}}$ is related by rated current of motor. Another Current command $i_{d s}^{s}$ has to be zero (set $d y=0$ ) for guaranteed the rotor state of being stationary. The output voltage vectors of the inverter are only switched by ull \& $u 4$ for the pseudo locked-rotor test. Complete control flow chart for the modified locked-rotor test is shown in Fig. $7(b)$.

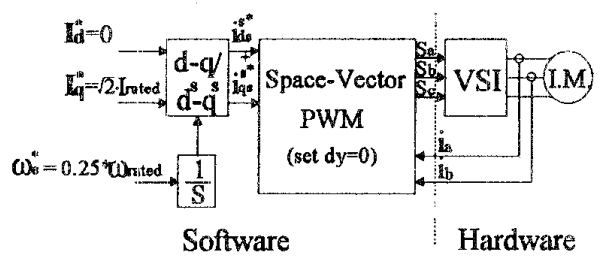

(a) Block diagram

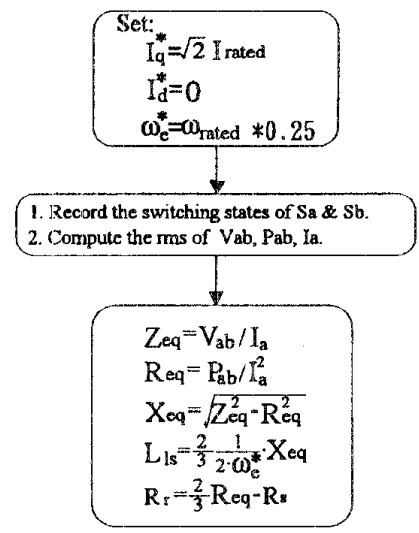

(b) Flow chart

Fig. 7 The modified locked-rotor test.

\section{EXPERIMENTS \& RESULT'S}

\section{A. Experimental Setup}

The test motor is three-phase Y-connected. Appendix gives the machine data. The three-phase test input is provided by a variable-voltage variable-frequency inverter with microprocessor-based control.

\section{B. Dc Test}

The stator resistance of $\mathrm{IM}$ is calculated by averaging the samples of terminal voltage and current. They are graphically depicted by Fig 8(a). After five hundred 
sampling, the average values of stator resistance will approach to a stable value.

The experiments are performed under three different switching frequencies. Fig. 8(b) gives the test recordings. Utilizing eq.(13), the computed dc stator resistance is $2.463 \Omega$.

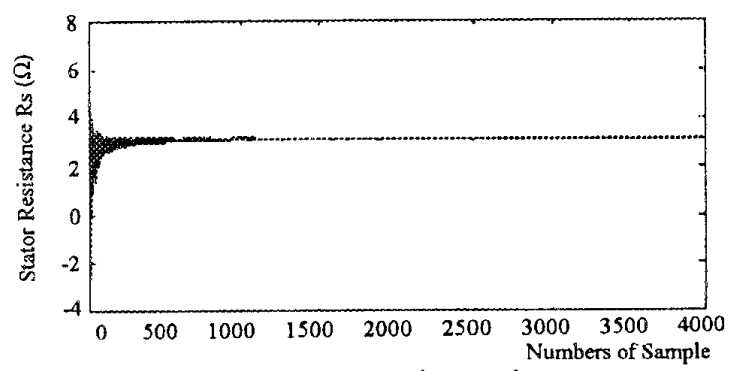

(a) Average resistance values

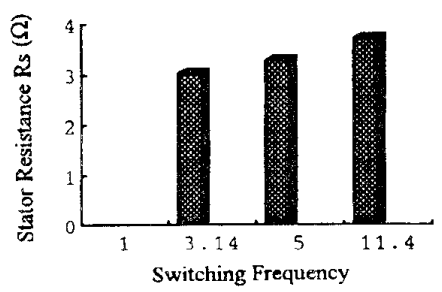

( $\mathrm{kHz})$

(b) Average resistance values under different switching frequency

Fig. 8 The result of modified de test.

\section{No-load Test}

The recordings of no-load test are shown in Fig 9(a) and (c). After three hundred samplings, the average values of $\mathrm{Id}^{*}$ and $\mathrm{L}_{\mathrm{s}}+\mathrm{Lm}$ are graphically described by Fig 9 (b) and Fig $9($ d), respectively.

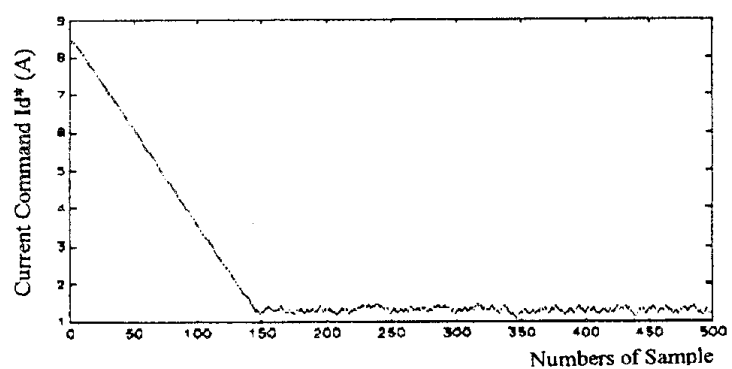

(a) Adjusting values of $\mathrm{Id}^{*}$

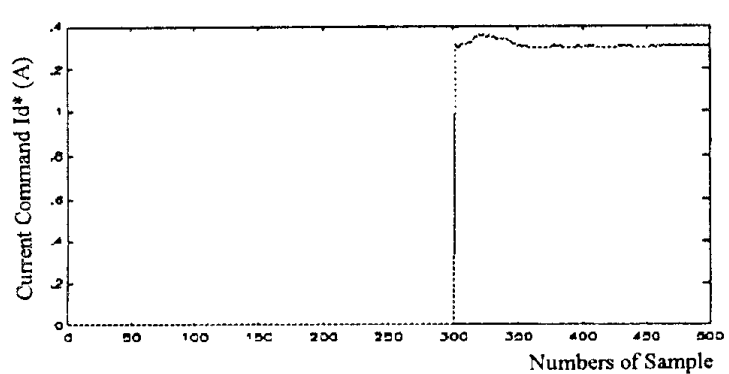

(b) Average values of Id*

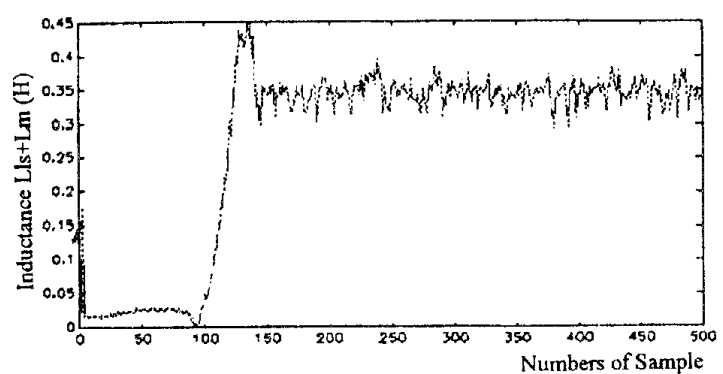

(c) Calculated Lls $+\mathrm{Lm}$

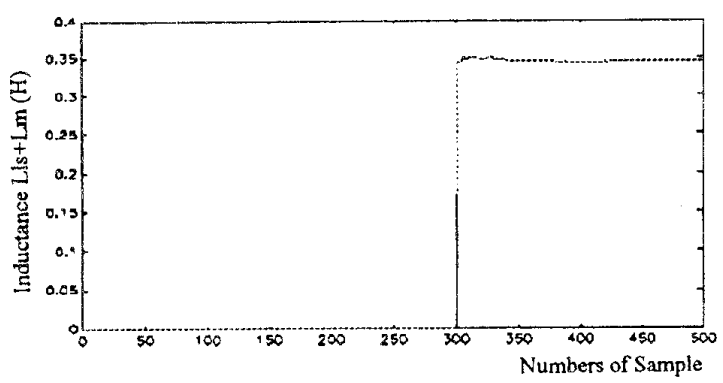

(d) Average values of $\mathrm{Lss}+\mathrm{Lm}$

Fig. 9 Recordings of modified no-load test.

\section{Locked-Rotor Test}

The locked-rotor test is performed at different input frequencies from 10 to $90 \mathrm{~Hz}$. The computed leakage inductance and equivalent resistance $\left(\mathrm{R}_{s}+\mathrm{R}_{r}\right)$ are graphically described by Fig. 10(a) and (b),respectively. Arrows point to $25 \%$ of the rated frequency. The leakage inductance and equivalent resistance drop as frequency increases.

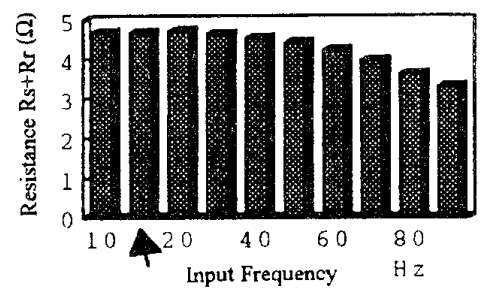

(a) Equivalent resistance under different input frequency

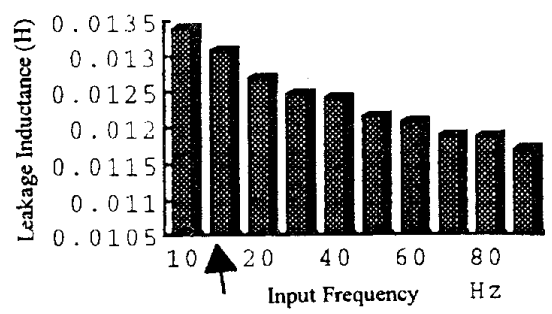

(b) Leakage inductance under different input frequency Fig. 10 The modifed locked-rotor test. 


\section{CONCLUSIONS}

A simple sensorless FOC with space-vector modulated current controller for automatic IM parameter measurement is presented. In this approach, no extra hardware or disconnection of electrical wires is required Only modification of commands in the FOC could complete the job for the dc test, the no-load test, and the locked-rotor test. The modified no-load test also provided a convenient approach to determine the exciting current command for field-roiented control. Laboratory experiments are performed. The effectiveness of the presented methods are verified by the experimental results.

\section{REFERENCES}

[1] E. Y. Y. Ho, P. C. Sen, "A microcontroller-based induction molor drive system using variable structure strategy with decoupling," $I E E E$ Trans. Industrial Electronics, Vol.37, No.3, pp.227-235, Jun. 1990.

[2] F. Blaschke, "The principle of field orientation as applied to the new transvector closed-loop control system for rotating-field machines," Siemens Rev., May 1972.

[3] T. Ohtani, N. Takada, K. Tanaka, "Vector control of induction motor without shaft encoder," in Conf. Rec. 1989 JEEE LAS Annu. Mig., pp.500-507.

[4] C Schauder, "Adaptive speed identification for vector control of induction motor without rotational transducers," in Conf. Rec. 1989 IEEE IAS Annu. Mtg., pp.493-499.

[5] X. Xu and D. W. Novotny, "Implementation of direct stator flux orientation control on a versatile DSP based system," in Conf. Rec. 1990 IEEE IAS Annu. Mtg., pp.404-409.
[6] H. Kubota, K. Matsuse, and T. Nakano, "DSP-based speed daptive flux observer of induction motor," IEEE Trans. Industrial Applications, Vol.29, No.2, pp.344-348, Mar./Apr. 1993.

[7] A. Gastli, N. Matsui, "Stator flux controlled V/f PWIM inverter with identification of IM parameters," IEEE Trans. Industrial Electronics, Vol.39, No.4, pp.334-340, Aug. 1992.

[8] S. J. Chapman, Electric Machinery Fundamentals, 2nd ed., McGraw-Hill, pp. \$83-616, 1991.

[9] C. L. Chen, Y. N. Lin, "Pseudo locked-rotor test for induction motor parameter measurements,". (to appear on IEEE Trans. Instrumentation \& Measurement.)

[10] B. K. Bose, Power electronics and ac drives, Prentice-Hall, 1986.

[11] M. P. Kazmierkowski, M. A. Dzieniakowski and W Sulkowski, "Novel space vector based current controllers for PWM-inverters," IEEE Trans. Power Electronics, Vol.6, no.1, pp.158-165, 1991.

[12] P. V. ONeil, Advanced enginerring mathematics, Wadsworth,1983

A. Induction Machine Data rated firequency: $60 \mathrm{~Hz}$ rated voltage: $220 / 380 \mathrm{~V}$ rated current: $8.6 / 5.0 \mathrm{~A}$ rated power: $2.2 \mathrm{~kW}$ at 1720 r.p.m.

B. Results of conventional tests -
$\mathrm{Rs}_{\mathrm{s}}=2.36 \Omega$.
$R_{r}=2.22 \Omega$
$L_{l s}=\mathrm{Llr}=10 \mathrm{mH}$
$L_{m}=342 \mathrm{mH}$ 